\title{
Lusioersily
}

\section{Androgen deprivation results in time-dependent hypoxia in LNCaP prostate tumours; informed scheduling of the bioreductive drug AQ4N improves treatment response.}

Ming, L., Byrne, N., Camac, SN., Ward, C., Mitchell, C., Waugh, D., McKeown, S., \& Worthington, J. (2013).

Androgen deprivation results in time-dependent hypoxia in LNCaP prostate tumours; informed scheduling of the bioreductive drug AQ4N improves treatment response. International Journal of Cancer, 132, 1323-1332.

Link to publication record in Ulster University Research Portal

Published in:

International Journal of Cancer

Publication Status:

Published (in print/issue): 01/01/2013

\section{Document Version}

Publisher's PDF, also known as Version of record

\section{General rights}

Copyright for the publications made accessible via Ulster University's Research Portal is retained by the author(s) and / or other copyright owners and it is a condition of accessing these publications that users recognise and abide by the legal requirements associated with these rights.

\section{Take down policy}

The Research Portal is Ulster University's institutional repository that provides access to Ulster's research outputs. Every effort has been made to ensure that content in the Research Portal does not infringe any person's rights, or applicable UK laws. If you discover content in the Research Portal that you believe breaches copyright or violates any law, please contact pure-support@ulster.ac.uk. 


\title{
Androgen deprivation results in time-dependent hypoxia in LNCaP prostate tumours: Informed scheduling of the bioreductive drug $A Q 4 \mathrm{~N}$ improves treatment response
}

\author{
Louise Ming ${ }^{1}$, Niall M. Byrne ${ }^{1}$, Sarah Nicole Camac ${ }^{1}$, Christopher A. Mitchell ${ }^{1}$, Claire Ward ${ }^{1}$, \\ David J. Waugh ${ }^{2}$, Stephanie R. McKeown ${ }^{1}$ and Jenny Worthington ${ }^{1}$ \\ ${ }^{1}$ Biomedical Sciences Research Institute, Centre for Molecular Biosciences, University of Ulster, Coleraine, Co-Londonderry, United Kingdom \\ ${ }^{2}$ Centre for Cancer Research and Cell Biology, Queens University Belfast, Belfast, Northern Ireland, United Kingdom
}

\begin{abstract}
Androgen withdrawal induces hypoxia in androgen-sensitive tissue; this is important as in the tumour microenvironment, hypoxia is known to drive malignant progression. Our study examined the time-dependent effect of androgen deprivation therapy (ADT) on tumour oxygenation and investigated the role of ADT-induced hypoxia on malignant progression in prostate tumours. LNCaP xenografted tumours were treated with anti-androgens and tumour oxygenation measured. Dorsal skin fold (DSF) chambers were used to image tumour vasculature in vivo. Quantitative PCR (QPCR) identified differential gene expression following treatment with bicalutamide. Bicalutamide-treated and vehicle-only-treated tumours were re-established in vitro, and invasion and sensitivity to docetaxel were measured. Tumour growth delay was calculated following treatment with bicalutamide combined with the bioreductive drug AQ4N. Tumour oxygenation measurements showed a precipitate decrease following initiation of ADT. A clinically relevant dose of bicalutamide $(2 \mathrm{mg} / \mathrm{kg} / \mathrm{day})$ decreased tumour oxygenation by $45 \%$ within $24 \mathrm{hr}$, reaching a nadir of $0.09 \%$ oxygen $(0.67 \pm 0.06 \mathrm{mmHg})$ by Day 7 ; this persisted until Day 14 when it increased up to Day 28. Using DSF chambers, LNCaP tumours treated with bicalutamide showed loss of small vessels at Days 7 and 14 with revascularisation occurring by Day 21. QPCR showed changes in gene expression consistent with the vascular changes and malignant progression. Cells from bicalutamide-treated tumours were more malignant than vehicle-treated controls. Combining bicalutamide with $\mathrm{AQ} 4 \mathrm{~N}(50 \mathrm{mg} / \mathrm{kg}$, single dose) caused greater tumour growth delay than bicalutamide alone. Our study shows that bicalutamide-induced hypoxia selects for cells that show malignant progression; targeting hypoxic cells may provide greater clinical benefit.
\end{abstract}

Hypoxia is a common feature of solid tumours and has been shown to drive malignant progression. ${ }^{1}$ Clinical studies have indicated that higher levels of hypoxia predict for poor local control and decreased disease free survival in patients with cancer. ${ }^{2}$ This may be particularly important in prostate cancer as these tumours show one of the lowest mean oxygen levels of any tumour type [ $2.4 \mathrm{mmHg} ; 0.32 \%$ oxygen partial pressure $\left.\left(\mathrm{pO}_{2}\right)\right]^{3}$ Indeed, increased hypoxia has been shown to correlate with clinical staging ${ }^{4}$ and biochemical failure after radiotherapy in patients with prostate cancer. ${ }^{5,6}$ In addi-

Key words: hypoxia, bicalutamide, malignant progression, bioreductive drug

Additional Supporting Information may be found in the online version of this article.

DOI: $10.1002 / \mathrm{ijc} .27796$

History: Received 4 Jan 2012; Accepted 6 Jul 2012; Online 23 Aug 2012

Correspondence to: Jenny Worthington, Biomedical Sciences Research Institute, Centre for Molecular Biosciences, University of Ulster, Cromore Road, Coleraine, Co-Londonderry BT52 1SA, United Kingdom, Tel.: +44-28-7012-3541, Fax: +44-28-7012-4375, E-mail: j.worthington@ulster.ac.uk tion, growing evidence supports the role of hypoxia in the malignant progression of the disease. ${ }^{7-9}$

Androgen deprivation therapy (ADT) has been the mainstay of treatment for locally advanced prostate cancer for many years. Although this treatment is initially successful, disease re-emergence occurs after a median of 18 months. ${ }^{10}$ This castrate-resistant form of the disease is more aggressive and is ultimately fatal; however, recent advances have identified approaches that have shown some improvements in response. ${ }^{11}$ The reason for the inevitable relapse has yet to be fully identified.

A number of laboratory studies have demonstrated that androgen withdrawal via castration or use of anti-androgens leads to a rapid decrease in blood flow to the normal rat prostate. $^{12,13}$ This is also accompanied by a reduction in microvessel density. ${ }^{14}$ Castration of mice bearing the androgen-sensitive Shionogi tumour resulted in a reduction in the number of tumour blood vessels ${ }^{15}$ and a decrease in tumour oxygenation $^{16}$ prior to tumour regression. A later rise in tumour oxygen levels was associated with re-growth.

We have previously demonstrated that exposure of LNCaP cells to cycles of hypoxia followed by reoxygenation leads to development of cells with an aggressive phenotype characterised by greater invasion, decreased sensitivity to apoptosis and 
What's new?

Standard androgen-deprivation therapy (ADT) can induce profound and persistent hypoxia within prostate-cancer tumors. Unfortunately, hypoxia can actually result in more aggressive tumors in many types of cancer. In this study, the authors found that combined treatment with ADT and the drug AQ4N (banoxantrone) improves primary tumor control and reduces metastatic spread in a mouse xenograft model of prostate cancer. (In hypoxic conditions AQ4N is reduced to AQ4, a highly cytotoxic compound.) These results provide proof of principle for targeting hypoxic cells in the treatment of prostate cancer.

androgen independence. ${ }^{17}$ Our study investigates the physiological effect of anti-androgens in prostate tumours in vivo, with specific interest in tumour hypoxia. The study identifies the time-dependent effect of ADT on tumour vasculature and oxygenation and strongly suggests that hypoxia may be the underlying mechanism for driving malignant progression seen in locally advanced prostate cancer after treatment with ADT.

Since we established that ADT results in profound and persistent hypoxia in bicalutamide-treated tumours, we carried out a pilot study to target these hypoxic cells using the bioreductive drug AQ4N (banoxantrone). We found that informed scheduling of $\mathrm{AQ} 4 \mathrm{~N}$ in combination with bicalutamide resulted in a greater tumour growth delay and reduced metastatic spread than with treating with bicalutamide alone.

The results from these studies demonstrate that selection of a targeting strategy based on longitudinal in vivo physiological data can significantly enhance the overall tumour response to bicalutamide.

\section{Material and Methods \\ Cell culture}

Parental LNCaP cells (ATCC, Rockville, MD) and generated sub-lines were maintained in RPMI-1640 medium supplemented with $10 \%$ foetal bovine serum, $10 \mathrm{mM}$ HEPES and 5 $\mathrm{mM}$ glucose (all from Invitrogen, Paisley, UK). All experiments were carried out at $37^{\circ} \mathrm{C}$ under $5 \% \mathrm{CO}_{2}$ in air.

\section{Drug preparation and administration}

Bicalutamide (Casodex; gift from AstraZeneca, Macclesfield, UK), finasteride (Sigma, Gillingham, UK) and flutamide (Sigma, Gillingham, UK) were prepared in vehicle $(0.1 \%$ dimethyl sulfoxide in corn oil) and administered orally (p.o.) at the doses identified in Table 1. For all longitudinal studies, vehicle or bicalutamide $(2 \mathrm{mg} / \mathrm{kg})$ was administered p.o. daily; the dose of $2 \mathrm{mg} / \mathrm{kg} /$ day is equivalent to a $50-\mathrm{mg}$ daily tablet in men. AQ4N (banoxantrone; a gift from Oncotherics, Shepsted, UK) was prepared in phosphate buffered saline (PBS) and was administered as a single bolus intraperitoneal injection $(50 \mathrm{mg} / \mathrm{kg})$.

\section{In vivo models}

All experiments were conducted in accordance with the Animal (Scientific Procedures) Act 1986 and the UKCCCR Guidelines (2010) for the welfare of animals in experimental neoplasia. ${ }^{18}$ LNCaP cells $\left(5 \times 10^{6}\right.$ in Matrigel $)$ were implanted on the rear dorsum of 8 - to 10 -week-old male
$\mathrm{Balb} / \mathrm{c}$ SCID mice. When tumour volume was $150-200 \mathrm{~mm}^{3}$, mice were randomly assigned to treatment groups.

Tumour oxygenation measurement. The $\mathrm{pO}_{2}$ of tumours was recorded using an Oxylite 2000 system (Oxford Optronix, Oxford, UK). Animals were secured into a bespoke restraining device with their tumours exposed. The fibre optic probe was inserted into a 21-gauge needle; this was placed into the tumour tissue. The needle was withdrawn and the probe was left to stabilise for $10 \mathrm{~min}$ before readings commenced. Thereafter, $\mathrm{pO}_{2}$ values were recorded every $15 \mathrm{sec}$ for 10 min. The readings were taken in two sites for each time point; final measures were an average of all readings.

Tumour growth delay. Tumour dimensions were measured using calipers, and the geometric mean diameter (GMD) was calculated using the following formula: GMD $=\sqrt[3]{ }$ length $\times$ breadth $\times$ height. Tumour volume was calculated using the following formula: $4 / 3 \pi r^{3}$, where $r=\mathrm{GMD} / 2$. Growth curves were drawn, and the time to double the initial treatment volume was calculated. Mice were treated as indicated in Figure 5, and they were sacrificed at Day 28.

Dorsal skin fold model. This involved surgically implanting a skin fold on the backs of 12-week-old Balb/c SCID mice as previously described. ${ }^{19}$ The specially designed window chamber (APJ Trading, Ventura, CA) contains a viewing port into which LNCaP tumour fragments were implanted on the exposed panniculus carnosus muscle. Following replacement of the cover slip and its securing with a c-clamp, the tumours were left for 7 days to vascularise. To assess changes in tumour vasculature, animals were given an i.v. injection of $150-\mathrm{kDa}$ FITC-labelled dextran ( $50 \mu \mathrm{l}, 50 \mathrm{mg} / \mathrm{ml}$; Sigma, Gillingham, UK) $15 \mathrm{~min}$ prior to imaging; the FITC signal was detected using a confocal microscope (Leica, Solmes, Germany). Sequential images of the implanted tumour fragments were taken at Day 0 and Days 7 , 14 and 21 following treatment. For each time point, images were taken from three sites on the tumour from five animals. Area covered by vessels was calculated using Image J software (NIH, Bethesda, MD). The results presented are an average \pm SE.

Assessment of metastasis. Male Balb/c SCID mice were implanted on the rear dorsum with luciferase-expressing LNCaP cells. The luciferase-expressing cells had similar characteristics to parental LNCaP cells (see Supporting Information Fig. S1). On Day 28 of treatment, animals were injected i.p. with a solution of D-luciferin (150 mg/kg in PBS) $15 \mathrm{~min}$ prior to imaging. Animals were then killed and a range of 
Table 1. Oxygenation of LNCaP tumour xenografts $24 \mathrm{hr}$ after exposure to androgen deprivation therapy

\begin{tabular}{lcll}
\hline Treatment & $\begin{array}{l}\text { Drug } \\
\text { dose } \\
(\mathrm{mg} / \mathrm{kg})\end{array}$ & $\begin{array}{l}{\mathrm{Mean} \mathrm{pO}_{2}}_{\text {value }} \\
(\mathrm{mmHg})\end{array}$ & $\begin{array}{l}p \text {-value } \\
\text { (compared to } \\
\text { zero time point) }\end{array}$ \\
\hline None (zero time) & 0 & $6.05 \pm 0.57$ & \\
\hline Vehicle & 0 & $5.7 \pm 0.86$ & 0.49 \\
\hline Finasteride & 50 & $5.50 \pm 0.76$ & 0.67 \\
\hline Flutamide & 10 & $2.65 \pm 0.32$ & 0.007 \\
\hline Flutamide & 25 & $0.97 \pm 0.14$ & 0.002 \\
\hline Bicalutamide & 2 & $2.92 \pm 0.33$ & 0.006 \\
\hline Bicalutamide & 10 & $0.73 \pm 0.12$ & 0.002 \\
\hline
\end{tabular}

Male SCID mice bearing tumours of $150-200 \mathrm{~mm}^{2}$ were assigned to the treatment groups indicated. Oxygen measurements were made before and $24 \mathrm{hr}$ after treatment using an Oxylite oxygen-sensing fibre optic probe. Data shown are the mean \pm SE $(n=5)$. The $p$-values were calculated using a two-tailed $t$-test.

tissues were removed for the detection of bioluminescence using the IVIS imaging system (Xenogen, Santa Clara, CA); only the lungs showed bioluminescence. Images were taken for $5 \mathrm{~min}$, and quantification of bioluminescence was achieved by drawing a region of interest around the area and measuring total flux in photons/second $(\mathrm{ph} / \mathrm{sec})$. The results shown are an average of five mice per treatment group.

\section{Immunohistochemistry}

Bicalutamide-treated (2 mg/kg, daily p.o.) and vehicle-onlytreated mice were culled on Day 0 and Days 7, 14, 21 or 28, and the LNCaP tumours were removed and subsequently fixed in formalin (10\%; Sigma, Gillingham, UK). Samples were wax embedded, sectioned at $5 \mu \mathrm{m}$ and dewaxed in $\mathrm{xy}-$ lene. Following rehydration in a descending series of ethanol followed by PBS washes, enzyme digestion was carried out using $0.4 \%$ pepsin (Sigma, Gillingham, UK) in $0.01 \mathrm{M} \mathrm{HCl}$ ( $\mathrm{pH} \mathrm{2.5)}$ for $30 \mathrm{~min}$. Endogenous peroxidases were blocked using 3\% hydrogen peroxide, and non-specific antibody binding was blocked using $1 \%$ bovine serum albumin (BSA). Sections were incubated with Glut1 primary antibody (1:400; Abcam, Cambridge, UK); BSA alone was used as a negative control. Sections were incubated with HRP-labelled secondary goat antibody (1:200; Abcam, Cambridge, UK), and staining was visualised using 3,3'-diaminobenzidine solution (Sigma, Gillingham, UK). Haemotoxylin was used as a counterstain.

Scoring of the extent and intensity of staining was carried out in five fields of view per section using a light microscope at a final magnification of $200 \times$. A total of two slides per tumour and five individual tumours per treatment group were quantified. The area of staining was assigned a value: $0-$ $5 \%=0 ; 6-25 \%=1 ; 26-75 \%=2$ and $>75 \%=3$. Intensity of staining assigned a value, none $=0$; light $=1$; medium $=$ 2 and dark $=3$, and added to the score for area of staining. Each section was scored in a blind manner by two independent observers, and the results were averaged. Inter-observer difference was $<10 \%$.

\section{Gene expression analysis}

Bicalutamide-treated (2 mg/kg, daily p.o.) and vehicle-only treated animals were culled at Day 0 and Days 7, 14, 21 and 28. Total RNA was extracted from tumour tissue using Trizol reagent (Invitrogen, Paisley, UK) according to the manufacturer's instructions. An aliquot containing $2 \mu \mathrm{g}$ of RNA was reverse transcribed with RevertAid ${ }^{\mathrm{TM}}$ reagent (Fermentas, Cambridge, UK) according to the manufacturer's instructions. The Lightcycler 480 system (Roche, Welwyn Garden City, UK) was used to perform quantitative PCR (QPCR) with Maxima ${ }^{\mathrm{TM}}$ Sybr green reagents (Fermentas Cambridge, UK) under the following conditions: $95^{\circ} \mathrm{C}$ for 2 min followed by 40 cycles of $95^{\circ} \mathrm{C}$ for $15 \mathrm{sec}, 60^{\circ}$ for $30 \mathrm{sec}$ and $72^{\circ}$ for $30 \mathrm{sec}$. In three independent experiments, three tumour samples were pooled giving a total of nine tumour samples. Each pooled sample was analysed in duplicate. Primer sets used for the study can be found in Supporting Information Figure S2.

\section{Western blotting}

Protein was extracted from tumour samples using a ProteoJET ${ }^{\mathrm{TM}}$ protein extraction kit (Fermentas, Cambridge, UK). A total of 60 $\mu \mathrm{g}$ of protein was electrophoresed on a $10 \%$ SDS-PAGE gel, transferred to polyvinylidene difluoride membrane (Millipore, Watford, UK) and probed with the primary antibody at the appropriate dilution: androgen receptor (AR) (1:1,000; Millipore, Watford, UK), interleukin 8 (IL-8) (1:1,000; AbD Serotec, Kidlington, UK), vascular endothelial growth factor (VEGF) (1:500; Santa Cruz, CA) and glyceraldehyde 3-phosphate dehydrogenase (GAPDH) (1:5,000; Cell Signaling, Beverley, MA). The levels of protein were measured using Supersignal Pico Chemiluminescent substrate (Pierce, Northumberland, UK) and Quantity One analysis software (BioRad, Bath, UK).

\section{Establishment of LNCaP-B1 and V1 sub-lines}

The LNCaP tumours treated in vivo with either bicalutamide ( $2 \mathrm{mg} / \mathrm{kg} /$ day; LNCaP-B1) or vehicle-only (LNCaP-V1) for 28 days were excised, homogenised and digested to produce a single cell suspension. These were then re-established in vitro using the same culture conditions as parental LNCaP cells.

\section{Cell doubling times}

Population doubling times were calculated following the use of the trypan blue exclusion assay on cell cultures. In brief, 35-mm dishes were plated with $2 \times 10^{5}$ ex vivo cultured cells, which were then incubated at $37^{\circ} \mathrm{C}$ in an atmosphere containing $5 \%$ $\mathrm{CO}_{2}$ in air. At 24, 48, 72 and $96 \mathrm{hr}$ after plating, adherent cells were trypsinised, stained with trypan blue and counted. Doubling times were calculated using the following formula: $N / N_{0}=$ $e^{k t}$, where $N$ is the cell number at time $t, N_{0}$ is the initial cell number (Time 0 ) and $k$ is a constant. The $k$ value was calculated for each time point between 24 and $96 \mathrm{hr}$, and an average value was used to calculate the time $t$ when $N / N_{0}=2$.

\section{In vitro cell invasion assay}

The capacity of LNCaP-B1 and LNCaP-V1 tumour cells to invade through Matrigel was determined using a cell invasion 
assay kit (Chemicon, Chandlers Ford, UK) according to the manufacturer's instructions. Briefly, cells were allowed to invade towards a chemical stimulus for $72 \mathrm{hr}$, and then invading cells were stained with crystal violet and counted. The results are an average of three independent experiments $\pm \mathrm{SE}$.

\section{XTT (2,3-bis-(2-methoxy-4-nitro-5-sulfophenyl)-2H- tetrazolium-5-carboxanilide) assay}

The viability of LNCaP-B1 and LNCaP-V1 tumour cells following treatment with docetaxel was measured using an XTT assay kit (Roche, Welwyn Garden City, UK). Briefly, cells were plated at $1 \times 10^{4}$ into individual wells of a 96-well plate and left to adhere overnight. Docetaxel (final concentration of $100 \mathrm{nM}$ ) was added, and then the cells were incubated for a further $48 \mathrm{hr}$. A $50-\mu \mathrm{l}$ aliquot of XTT solution was added to each well, and the plate was returned to the incubator for $3 \mathrm{hr}$ at $37^{\circ} \mathrm{C}$. The absorbance of each well was measured at $494 \mathrm{~nm}$ using a Fluorostar Omega plate reader (BMG Labtech, Aylesbury, UK). Viability was expressed as the mean \pm SE percentage of the untreated controls from three independent experiments.

\section{SiRNA transfection}

The appropriate number of cells were plated in antibioticfree medium $16 \mathrm{hr}$ prior to transfection. All materials for siRNA transfection were obtained from Santa Cruz, Beverley, $\mathrm{MA}$, and used according to the manufacturer's instructions. siRNA control samples contained a scrambled sequence that does not lead to specific degradation of any known cellular mRNA; this was used as a negative control.

\section{Statistical analysis}

Comparisons between datasets from in vitro QPCR analysis, in vivo oxygenation of tumour xenografts (Table 1), tumour growth delay and quantification of bioluminescence were carried out using a two-tailed $t$-test. All other datasets were analysed using a two-way ANOVA with post hoc Bonferroni analysis. All statistical analyses were carried out using Prism 5.0 .

\section{Results \\ Interference with androgen signalling causes a decrease in tumour $\mathrm{pO}_{2}$ levels}

LNCaP tumour-bearing mice were treated with three drugs that reduce the effects of androgens on tumours, and intratumour $\mathrm{pO}_{2}$ levels were measured both before and after 24 $\mathrm{hr}$ of treatment. Tumours had a $\mathrm{pO}_{2}$ value of $6.05 \pm$ $0.57 \mathrm{mmHg}$ before treatment (Table 1). Small but non-significant changes in $\mathrm{pO}_{2}$ levels were observed in tumours treated with vehicle-only $(p=0.49)$ or finasteride $(p=0.67)$. Treatment with flutamide resulted in a significant decrease in tumour $\mathrm{pO}_{2}$ at both $10 \mathrm{mg} / \mathrm{kg}(2.65 \pm 0.32 \mathrm{mmHg})$ and 25 $\mathrm{mg} / \mathrm{kg}(0.97 \pm 0.14 \mathrm{mmHg})$. Bicalutamide also caused a significant drop in $\mathrm{pO}_{2}$ using either $10 \mathrm{mg} / \mathrm{kg}(0.73 \pm 0.12$
$\mathrm{mmHg}$ ) or the more clinically relevant dose of $2 \mathrm{mg} / \mathrm{kg}$ $(2.92 \pm 0.33 \mathrm{mmHg})$ within $24 \mathrm{hr}$ of treatment.

\section{Bicalutamide alters LNCaP tumour $\mathrm{pO}_{2}$ levels in a time- dependent manner}

The $\mathrm{pO}_{2}$ of LNCaP tumours was measured longitudinally from Day 0 to Day 28 in individual tumours. Initial tumour $\mathrm{pO}_{2}$ readings in vehicle-treated $(5.85 \mathrm{mmHg})$ and bicalutamide-treated (5.75 mmHg) groups were similar $(p=0.31)$, and this remained constant in the vehicle-treated animals for the duration of the study (Fig. 1a). However, daily bicalutamide ( $2 \mathrm{mg} / \mathrm{kg}$, p.o.) caused an immediate and profound decrease in tumour $\mathrm{pO}_{2}$. This dropped by $45 \%$ of pre-treatment values within the first 24 $\mathrm{hr}$, and then the levels continued to fall precipitously; by Day 7 , $\mathrm{pO}_{2}$ values were approximately tenfold less than at Day 0 , that is, $0.09 \%$ oxygen $(0.67 \pm 0.06 \mathrm{mmHg})$. Figure $1 b$ illustrates this fall with a dramatic shift in the relative frequency distribution of oxygen within these tumours. This nadir persisted until at least Day $14(0.65 \pm 0.06 \mathrm{mmHg})$ after treatment; however, by Day 17 , oxygenation began to increase and gradually rose until the end of the study despite the continuation of daily bicalutamide treatment (Fig. 1a).

Glut1 staining was used to confirm the presence of hypoxia during treatment with bicalutamide. Weak Glut1 staining was observed in tumour samples before treatment; this level was maintained in all vehicle-treated tumours throughout the study (Fig. 1c). Using a semi-quantitative method to score Glut1 staining, no significant change was observed throughout the study in vehicle-treated tumours $(p \geq 0.05$ in all cases; Fig. 1d). In bicalutamide-treated tumours, the intensity and area of staining changed along the time course (Figs. $1 c$ and $1 d$ ). After 7 and 14 days of treatment, large areas of dark staining were observed; this was significantly different from that observed in vehicle-treated tumours. On Days 21 and 28, the semi-quantitative measurement of Glut1 staining in sections from bicalutamide-treated tumours was not significantly different than that observed in vehicle-treated tumours.

\section{Bicalutamide alters the number of tumour microvessels in a time-dependent manner}

LNCaP tumour fragments were implanted into the dorsal skin fold (DSF) of Balb/c SCID mice and allowed to vascularise for 7 days; at this time (designated as treatment day 0), the tumours were well vascularised (Fig. $2 a$ ). When tumours were treated with vehicle, the vascular network was maintained throughout the experiment (21 days). However, after 7 days of treatment with bicalutamide $(2 \mathrm{mg} / \mathrm{kg} /$ day $)$, loss of small blood vessels was observed, which was more pronounced by Day 14 . After 21 days of bicalutamide treatment, the larger vessels were still prominent; however, many smaller vessels were reestablished and small sprouting vessels can be seen.

The surface area covered by blood vessels was analysed for each time point during treatment (Fig. $2 b$ ). Initial coverage by blood vessels was similar in both vehicle-treated $\left(3.3 \times 10^{3}\right.$ $\left.\mu \mathrm{M}^{2}\right)$ and bicalutamide-treated $\left(3.0 \times 10^{3} \mu \mathrm{M}^{2}\right)$ tumours. In 
a

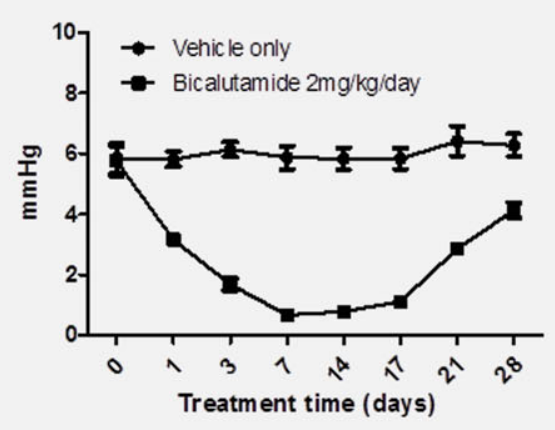

$b$ (i)

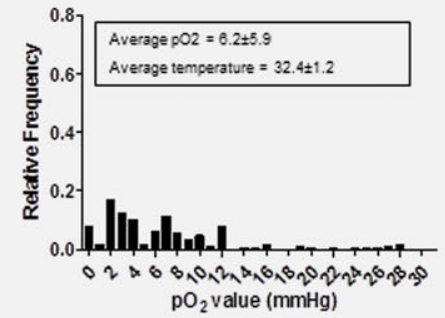

(ii)

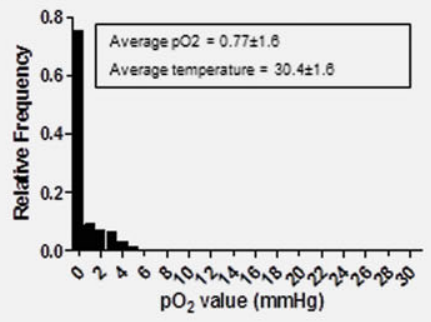

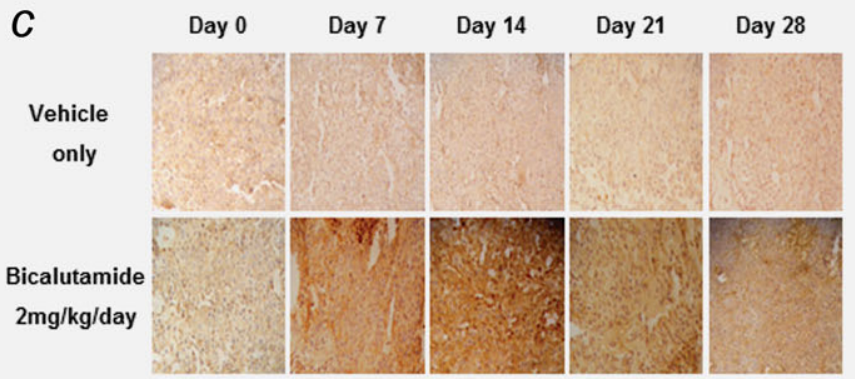

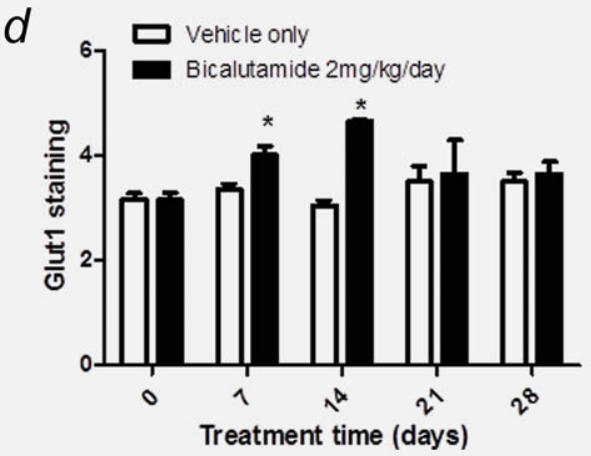

Figure 1. Changes in $\mathrm{pO}_{2}$ levels in $\mathrm{LNCaP}$ tumour xenografts during daily bicalutamide treatment. Male Balb/c SCID mice bearing tumours of 150-200 $\mathrm{mm}^{2}$ were used. (a) Oxylite electrode measurements of $\mathrm{pO}_{2}$ levels in both vehicle-treated and bicalutamide-treated (2 mg/ $\mathrm{kg}$ ) $\mathrm{LNCaP}$ tumours were taken on the indicated days. The results shown are mean \pm SE $(n=10)$. $(b)$ Representative histograms of the relative frequency of $\mathrm{pO}_{2}$ measurements of LNCaP tumours treated with (i) vehicle and (ii) bicalutamide after 7 days of treatment. (c) Glut1 staining of LNCaP tumour xenografts treated with vehicle and bicalutamide (magnification: $\times 20$ ). (d) Semi-quantitative analysis of Glut1 staining in LNCaP tumours during bicalutamide treatment. The results shown are mean $\pm \mathrm{SE}(n=5)$; ${ }^{\star} p \leq 0.05$ (two-way ANOVA).

vehicle-treated animals, a typical vascular pattern was observed with the proportion of tumour area covered by vessels rising gradually throughout the course of the experiment. However, after 7 days, bicalutamide treatment coverage was $1.6 \times 10^{3}$ $\mu \mathrm{M}^{2}$ compared to $3.8 \times 10^{3} \mu \mathrm{M}^{2}$ in vehicle-treated tumours $(p$ $\leq 0.05)$. This surface area was maintained following 14 days bicalutamide treatment compared to $5.2 \times 10^{3} \mu \mathrm{M}^{2}$ in vehicletreated tumours $(p \leq 0.01)$; the vessels that remained were mainly large vessels with very few smaller capillaries. Following 21 days of bicalutamide treatment, the area covered by blood vessels had risen to $4.8 \times 10^{3} \mu \mathrm{M}^{2}$; however, this was still significantly different from the control tumours $(p \leq 0.05)$.

\section{Gene expression profiles change over time in bicalutamide-treated tumours}

QPCR was used to assess the effect of bicalutamide-induced hypoxia on the expression of a selection of genes involved with angiogenesis and prostate tumour malignant progression. From Day 14 of bicalutamide treatment, tumour-associated androgen receptor levels were higher than in those treated with vehicle-only; however, these did not reach statistical significance (Fig. $3 a$ ).

The expression of the pro-angiogenic VEGF mRNA followed the pattern of blood vessel density in the DSF model with levels decreasing significantly after 7 days of bicalutamide treatment (Fig. 3b). Maximal expression was observed at 21 days of bicalutamide treatment with VEGF mRNA levels $\sim 2.5$-fold higher than in vehicle-only controls.

IL-8 mRNA expression in vehicle-treated tumours increased slightly during the study. In bicalutamide-treated samples, IL-8 mRNA expression was significantly less than in vehicle-treated controls at Day 14 (Fig. 3c). By Day 21, IL-8 mRNA expression in bicalutamide-treated tumours had risen very significantly to 3.9 -fold higher than Day 0 controls ( $p \leq$ 0.001 ); this corresponded to the angiogenic burst observed in the DSF.

Bcl-2 mRNA levels decreased significantly in bicalutamide-treated tumours after 7 days (Fig. $3 d$ ). By 21 days of bicalutamide treatment, Bcl-2 mRNA was 2.9-fold higher than in vehicle-treated tumours $(p \leq 0.001)$. Although Bcl-2 mRNA levels in bicalutamide-treated tumours were slightly reduced at Day 28, they were still significantly higher than in vehicle-treated tumours $(p \leq 0.01)$.

\section{Bicalutamide treatment in vivo selects for LNCaP cells with an aggressive phenotype}

Tumour tissue was excised from mice treated for 28 days with either vehicle-only (LNCaP-V1) or bicalutamide $(2 \mathrm{mg} / \mathrm{kg} /$ day $)$ 


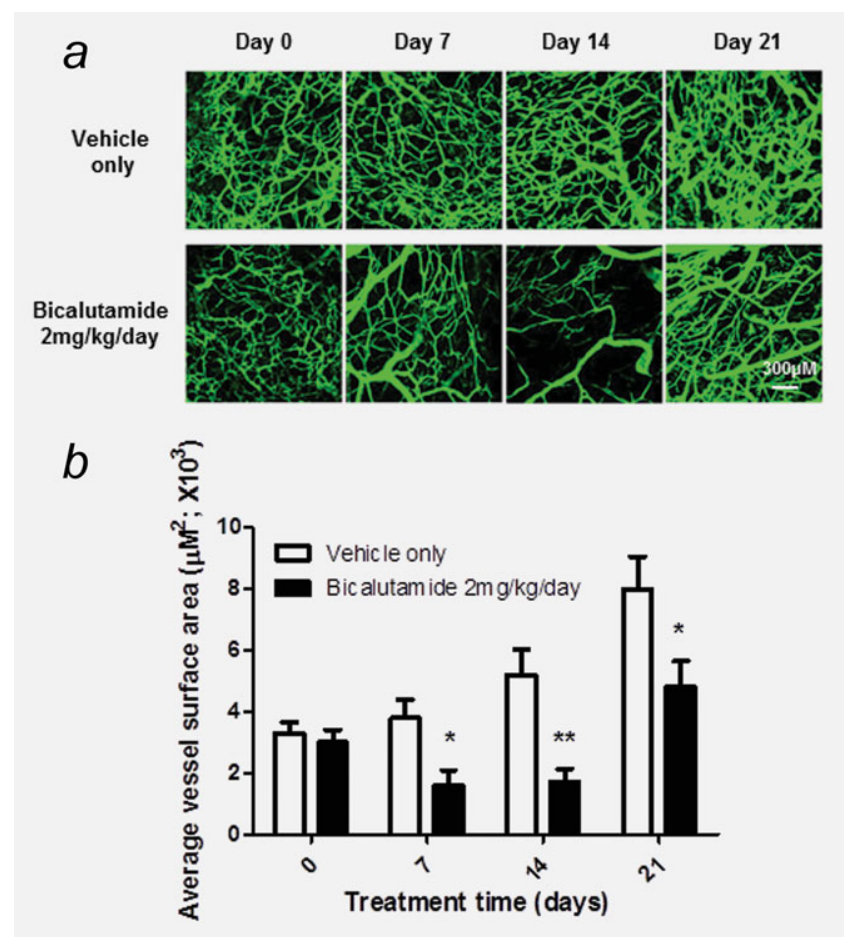

Figure 2. The effect of daily bicalutamide treatment on the vasculature of LNCaP tumour xenografts. An LNCaP tumour fragment was implanted onto the dorsal skin fold of male Balb/c SCID mice. (a) Tumour fragments were allowed to vascularise for 7 days. The vasculature was imaged using a confocal microscope by i.v. injection of FITC-dextran 15 min prior to imaging. This was carried out prior to commencement of treatment (Day 0) and after 7,14 and 21 days in both vehicle- and bicalutamide-treated mice ( $2 \mathrm{mg} / \mathrm{kg} /$ day). (b) Changes in area covered by blood vessels during bicalutamide treatment. The results shown are mean \pm SE $(n=5) ;{ }^{*} p \leq 0.05,{ }^{* *} p \leq 0.01$ (two-way ANOVA).

(LNCaP-B1). The cells were re-established in vitro, and the population doubling times were assessed using the trypan blue exclusion assay. Both cell lines had similar doubling times in normal culture medium $(36.1 \pm 6.1 \mathrm{hr}$ for LNCaP$\mathrm{B} 1$ and $37.8 \pm 5.6 \mathrm{hr}$ for LNCaP-V1); however, in charcoalstripped medium (which removes androgenic growth factors), the doubling times were significantly different $(43.0 \pm 2.2 \mathrm{hr}$ for LNCaP-B1 and $50.2 \pm 3.4 \mathrm{hr}$ for LNCaP-V1; $p=0.033$ ).

The protein and mRNA levels of a number of genes associated with malignant progression were assessed in the cell lines (Figs. $4 a$ and $4 b$ ). The levels of the pro-apoptotic Bax protein and mRNA were reduced in the LNCaP-B1 sub-line; conversely, mRNA and protein levels of the anti-apoptotic Bcl-2 were increased twofold. The levels of IL- 8 and AR were 3.6- and 1.8-fold higher in LNCaP-B1 cells compared to LNCaP-V1s.

Cell viability after treatment with docetaxel $(100 \mathrm{nM})$ was assessed using the XTT assay. A significant increase in viability was observed in LNCaP-B1 compared to LNCaP-V1 cells (Fig. 4c). Treating the LNCaP-B1 cells with siRNA-targeting $\mathrm{Bcl}-2$ tested the role of increased $\mathrm{Bcl}-2$ in the observed resist- ance to docetaxel. Sensitivity to docetaxel increased (Fig. 4c) after Bcl-2 siRNA reduced Bcl-2 expression by $80 \%$ (Fig. $4 d$ ).

As increased invasion is a hallmark of more malignant cells, the invasive capacity of LNCaP-B1 and LNCaP-V1 cells was compared using an in vitro assay. More LNCaP-B1 cells invaded through the Matrigel ${ }^{\circledR}$ membrane than LNCaP-V1 cells $(p \leq 0.001$; Fig. $4 e$ ). To assess the role of IL-8 in the increased invasion, LNCaP-B1 cells were treated with IL-8 siRNA. The invasion capacity of LNCaP-B1 cells transfected with scrambled siRNA was unchanged from untreated B1 cells ( $p=0.1$ ); however, the inhibition of IL-8 using siRNA reduced invasion by $73 \% \pm 3 \%$. Protein expression studies confirmed almost complete blockade of IL-8 expression (Fig. 4f).

\section{Informed scheduling of the bioreductive drug AQ4N increases the effectiveness of bicalutamide treatment}

As we observed a large drop in tumour oxygenation following bicalutamide treatment, we investigated the effect of administering the bioreductive drug AQ4N with bicalutamide. We used the oxygenation data obtained in Figure $1 a$ to generate an informed schedule of treatment, which consisted of 28 days of bicalutamide treatment at $2 \mathrm{mg} / \mathrm{kg} /$ day with AQ4N (50 mg/ $\mathrm{kg}$ ) given once via i.p. injection on Day 7. Mice treated with bicalutamide-only demonstrated a reduction in tumour growth up to Day 12/14 (Fig. 5a), after which the tumour volume rapidly increased. By Day 28, bicalutamide-only treated tumours were the same size as vehicle-only controls. Treatment with AQ4N combined with bicalutamide resulted in LNCaP tumours that grew significantly slower than those treated with either vehicle-only or bicalutamide. Mice treated with vehicle-only reached double their treatment starting volume at $11.4 \pm 0.5$ days (Fig. $5 b$ ); however, this was not statistically different from those animals treated with vehicle and AQ4N $(p=0.82)$. Treatment with bicalutamide resulted in a significant tumour growth delay of $5.1 \pm 2.9$ days $(p=0.04)$. Tumours treated with bicalutamide and AQ4N had the largest tumour growth delay of $15.1 \pm 4.2$ days $(p=0.018)$.

Metastasis was assessed at 28 days in all groups to identify if spread was influenced by treatment over the same time period. The only site where metastatic cells were found was in the lungs (Fig. $5 c$ ). Mice treated with bicalutamide had the greatest bioluminescence $\left(6.93 \pm 2.09 \times 10^{5} \mathrm{ph} / \mathrm{sec}\right.$; Fig. $\left.5 d\right)$; however, this was not statistically different from those mice treated with vehicle-only $\left(5.875 \pm 2.34 \times 10^{5} \mathrm{ph} / \mathrm{sec} ; p=\right.$ 0.45). Mice treated with AQ4N-only had the least amount of bioluminescence $\left(1.99 \pm 1.64 \times 10^{5} \mathrm{ph} / \mathrm{sec}\right)$; however, this was significantly less than those treated with bicalutamide $(p$ $=0.002$ ). Combining bicalutamide treatment with AQ4N resulted in less bioluminescence than observed in bicalutamide-treated animals $\left(3.08 \pm 1.84 \times 10^{5} \mathrm{ph} / \mathrm{sec} ; p=0.013\right)$.

\section{Discussion}

Bicalutamide is a widely used drug for the treatment of locally advanced prostate cancer. Although sometimes it is used as a single agent, often bicalutamide is combined with 

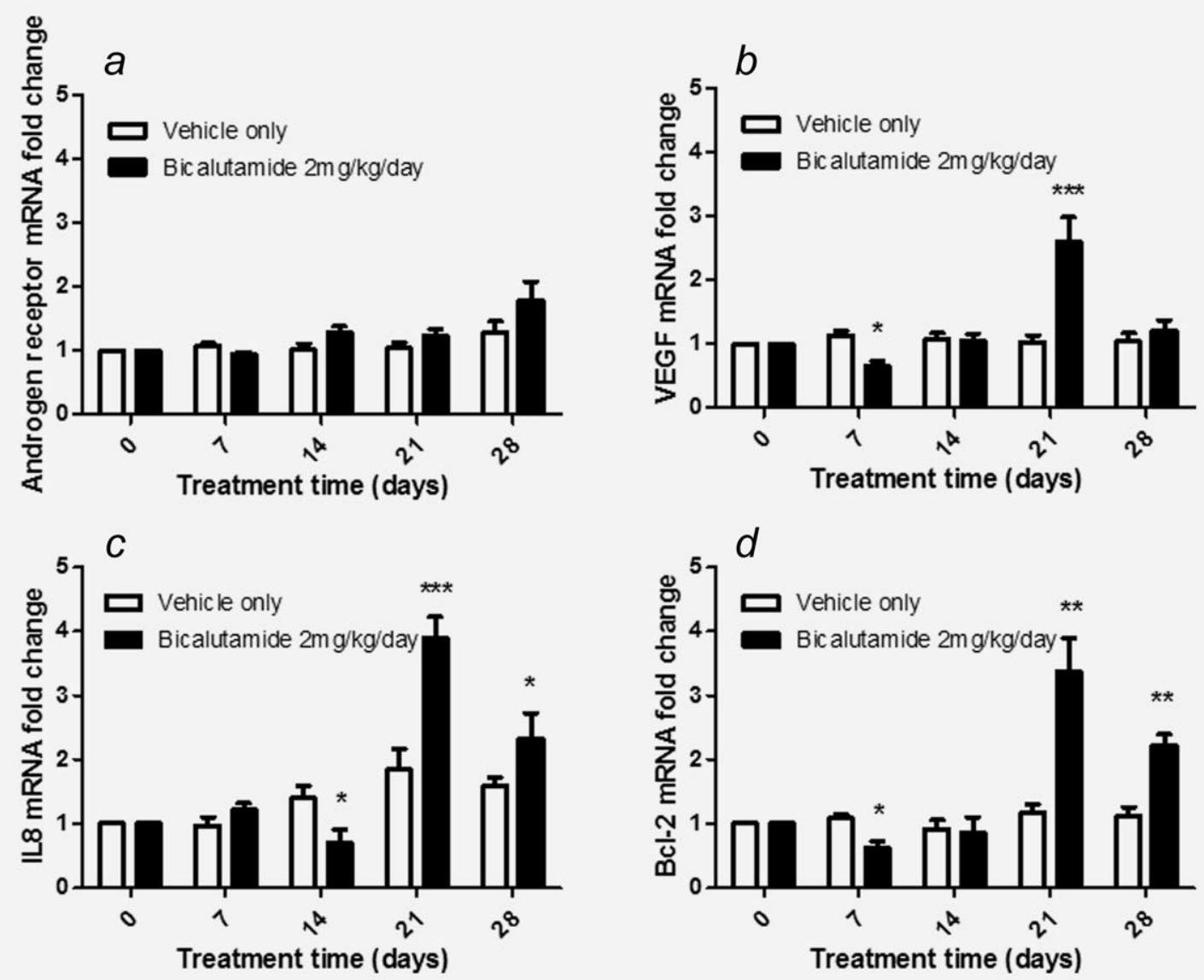

Figure 3. The effect of daily bicalutamide treatment on gene expression in LNCaP tumour xenografts. Male Balb/c SCID mice bearing tumours of $150-200 \mathrm{~mm}^{2}$ were treated with vehicle or bicalutamide $(2 \mathrm{mg} / \mathrm{kg} / \mathrm{day}$ ) for 28 days. At various time points during treatment, animals were killed and RNA was extracted from the tumour. QPCR was used to measure gene expression of $(a)$ androgen receptor, $(b)$ VEGF, (c) IL-8 and (d) Bcl-2. The results shown are mean \pm SE of three pools of tumours; ${ }^{\star} p \leq 0.05,{ }^{\star \star} p \leq 0.01,{ }^{\star \star \star} p \leq 0.001$ (two-way ANOVA).

an lutenising hormone releasing hormone (LHRH) antagonist and/or radiotherapy; usually, these modalities are used 2 weeks and 1-3 months, respectively, after the initiation of bicalutamide treatment. ${ }^{20}$ Our study provides direct evidence that immediately following initiation of a clinically relevant bicalutamide treatment regimen, there is a collapse of the tumour vasculature resulting in a profound decrease in tumour oxygenation to a nadir of $0.05 \%$ oxygen $(0.67 \pm 0.06$ $\mathrm{mmHg}$ ) on Day 7. Despite exposure to such profound hypoxia for 7-10 days, our data indicate that a proportion of tumour cells were able to survive the onset of hypoxia and through genetic selection/modification were able to promote tumour reoxygenation through stimulation of revascularisation (Fig. 2). This resulted in growth of a more malignant androgen-insensitive tumour (Fig. 4).

Oxygenation readings in LNCaP xenografts demonstrated that, with the exception of finasteride, a range of drugs that interfere with androgen activity have the ability to significantly decrease tumour oxygenation within a very short time $(24 \mathrm{hr})$ of treatment initiation (Table 1). Previous studies have shown that finasteride produces similar effects to bicalu- tamide and flutamide in reducing blood flow and microvascular density in normal rat prostate. ${ }^{11-13}$ These studies were performed over a longer time frame than our experiments, and therefore, it is feasible that the effects from finasteride treatment take longer than $24 \mathrm{hr}$ to appear, possibly due to its different mechanism of action.

The initial biphasic oxygenation response seen in the LNCaP xenograft model may also occur in patients; currently, there is no direct evidence of this. However, Ohlson et $a .^{21}$ reported a significant drop in tumour cell proliferation and an increase in apoptosis 3-4 days after castration of men with prostate cancer. These parameters returned to normal within 10 days. Although indirect, this study indicates a slowing of growth and an increase in cell death at the same time that our study shows the development of severe hypoxia following bicalutamide administration.

Although clinical measurements of tumour hypoxia following $\mathrm{AD}$ are conflicting, a study in 22 patients reported an increase in prostate tumour oxygenation 30 days after androgen withdrawal; however, there was considerable heterogeneity of response. ${ }^{22}$ Although this study seems contradictory to 
a

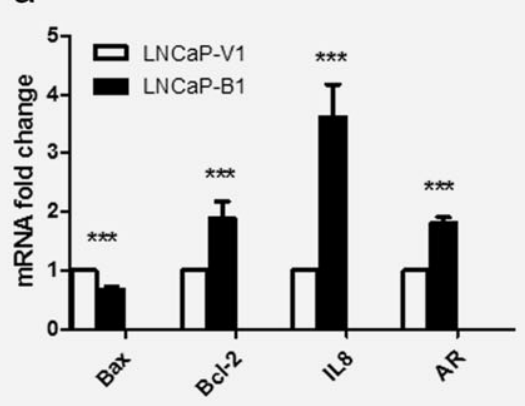

$b$
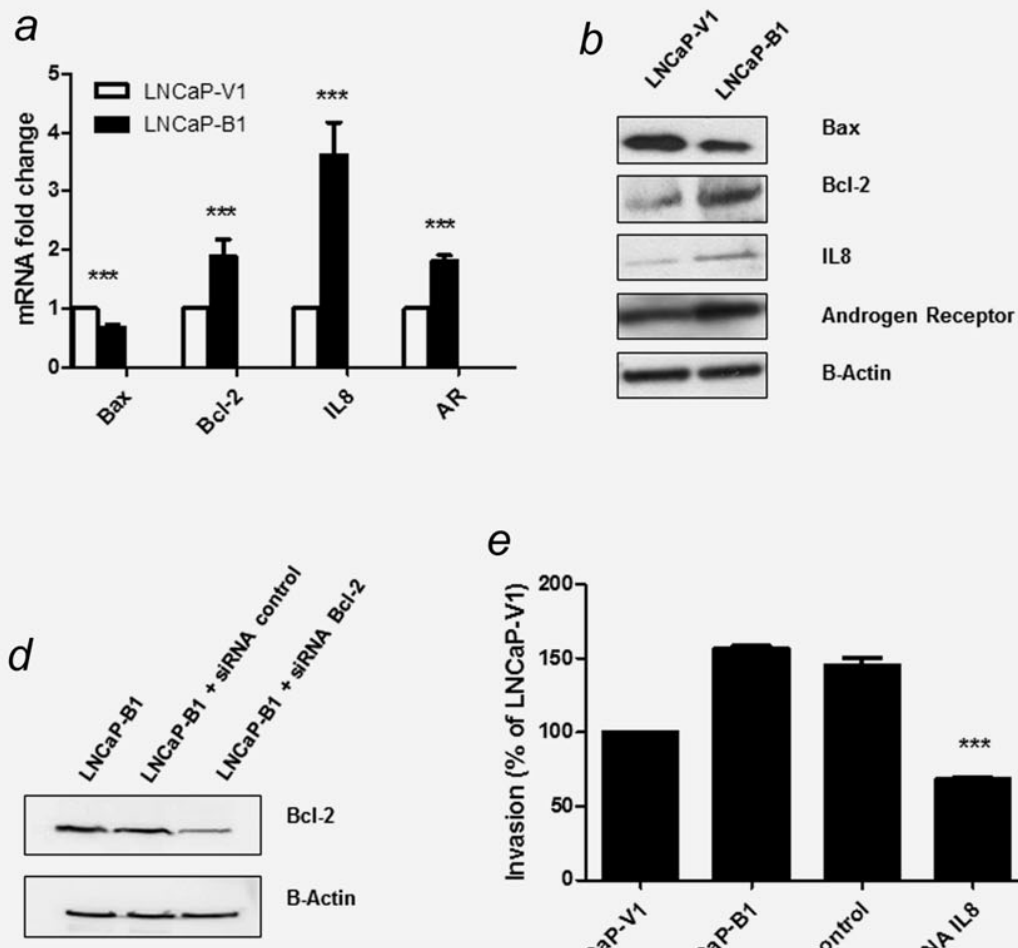

e

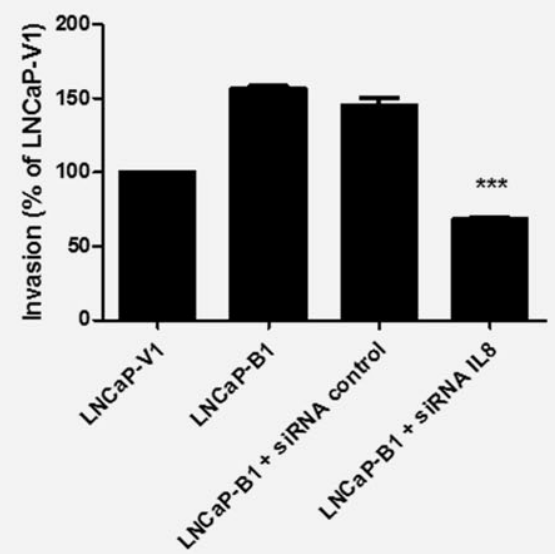

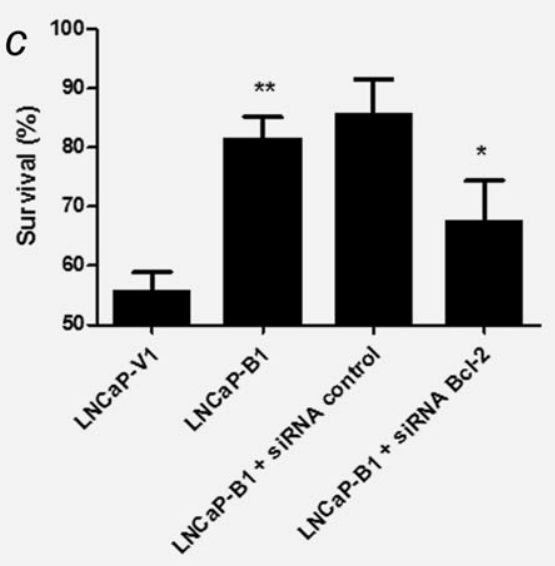

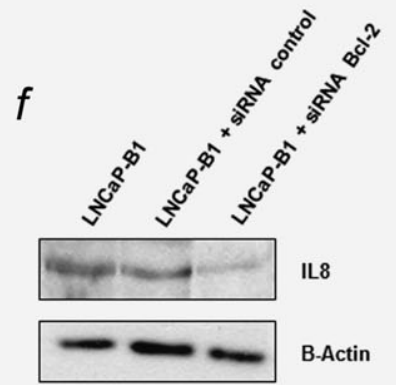

Figure 4. Comparison of LNCaP tumour cells in ex vivo culture excised following 28 days of daily treatment with vehicle or bicalutamide. Mice bearing LNCaP tumours were treated with either vehicle (LNCaP-V1) or bicalutamide ( $2 \mathrm{mg} / \mathrm{kg} / \mathrm{day}$ ) (LNCaP-B1) for 28 days. Cells were re-established in culture after digestion with an enzyme cocktail. Comparison of expression levels of various genes measured by (a) QPCR and $(b)$ Western blotting. (c) Sensitivity of LNCaP-V1, LNCaP-B1 and LNCaP-B1 cells treated with Bcl-2 siRNA to treatment with docetaxel was assessed using an XTT assay. The results shown are the mean $\pm \mathrm{SE}$ of three independent experiments. (d) Levels of $\mathrm{Bcl}-2$ protein in LNCaP-B1 cells following Bcl-2 siRNA treatment. (e) In vitro invasion of LNCaP-V1, LNCaP-B1 and LNCaP-B1 cells treated with IL-8 siRNA. Data points are the mean \pm SE of 3 independent experiments. ( $f$ ) Levels of IL-8 protein in LNCaP-B1 cells following siRNA IL-8 treatment. ${ }^{\star \star *} p \leq 0.001$ (two-tailed $t$-test).

our results, the earliest time point measured in the clinical study was 30 days (ranging up to 135 days) after ADT was initiated. It is therefore possible that an initial drop in $\mathrm{pO}_{2}$ was not detected due to the latent analysis of the tumours. Additionally, a recent study in 14 patients showed that HIF1$\alpha$ protein expression dropped following castration ${ }^{23}$; however, again the earliest time point examined was 1 month following surgery. Conversely, Alonzi et al. ${ }^{24}$ studied patients with prostate cancer who were treated with daily bicalutamide and an additional depot injection of goserelin acetate (Zoladex) at 14 days. Using multiparameter MRI, they showed a drop in blood flow and features of increased hypoxia, which were maintained throughout the 3-month follow-up.

It is worth noting that our experiments were carried out in an animal model using LNCaP cells that are metastatic (albeit weakly) and, therefore, may not be fully representative of the clinical scenarios reported by Milosevic and Alonzi. The already metastatic nature of the model cell line may explain the increased metastases following ADT in our system, which is seemingly at odds with the clinical scenario using neoadjuvant ADT prior to radiotherapy. ${ }^{25}$ However, patients do eventually relapse and develop metastatic disease; the difference in time frame between these observations in our animal model and that observed in the clinic is a feature of preclinical models.

Consistent with the latent re-vascularisation of the tumours observed $>14$ days post-ADT, we detected increased expression of the pro-angiogenic factors VEGF and IL-8 in excised tumour material. Furthermore, analysis of tumour cells that were re-established from a tumour treated in vivo with bicalutamide (LNCaP-B1) demonstrated evidence of molecular and cellular adaptation to treatment. Cells exposed to bicalutamide grew significantly better in charcoal-stripped medium than vehicle-treated tumour cells (LNCaP-V1), showing that selection had occurred for cells that were less dependent on androgen for growth. Additionally, increased Bcl-2 mRNA was observed in both LNCaP tumours treated with bicalutamide and bicalutamide-treated tumour cells reestablished in cell culture (LNCaP-B1). An increase in Bcl-2 

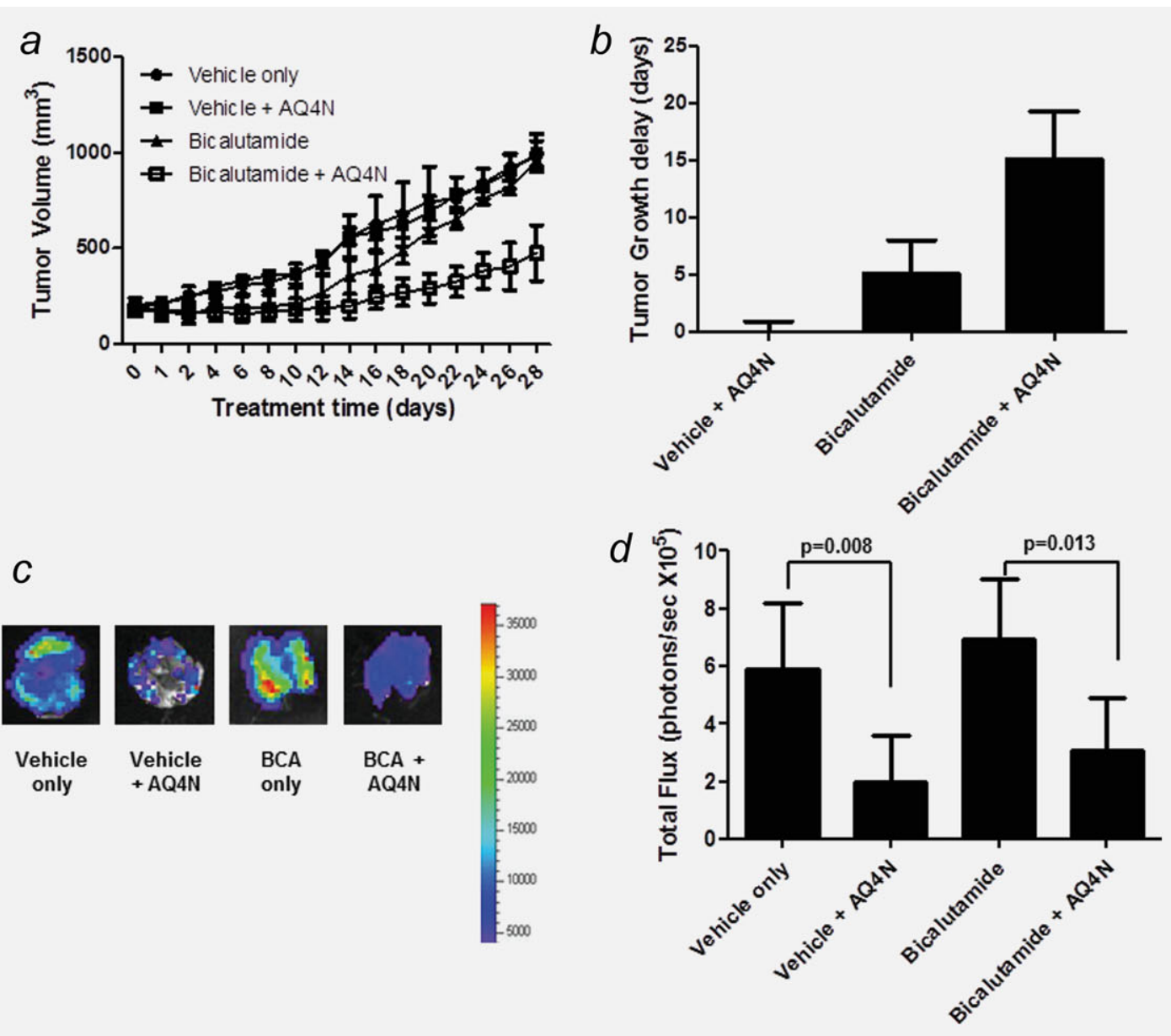

Figure 5. The effect of combining bicalutamide and a bioreductive drug (AQ4N). Male SCID mice bearing tumours of $150-200 \mathrm{~mm}^{2}$ were assigned to treatment groups: vehicle-only, vehicle + AQ4N $(50 \mathrm{mg} / \mathrm{kg})$, bicalutamide only $(2 \mathrm{mg} / \mathrm{kg} / \mathrm{day})$ and bicalutamide $(2 \mathrm{mg} / \mathrm{kg} / \mathrm{day})$ + AQ4N $(50 \mathrm{mg} / \mathrm{kg})$. AQ4N was given by i.p. injection once on Day 7. (a) Tumour growth curves were obtained by measuring tumour volume every 2 days until Day 28. The results represent the mean \pm SE $(n=5)$. (b) Delay in the time for LNCaP tumours to reach double their treatment volume. (c) Representative bioluminescence images of lungs from treated animals. (d) Quantification of bioluminescence. The results shown are mean \pm SE $(n=5)$.

expression is a key molecular change in the progression of prostate cancer $^{26}$ and increases resistance to apoptosis. We demonstrated that LNCaP-B1 cells were significantly more resistant to docetaxel than $\mathrm{LNCaP}-\mathrm{V} 1$ cells; this was abolished following siRNA Bcl-2 treatment. These results are of clinical significance as docetaxel is one of the drugs used in patients who relapse with a castrate-resistant tumour after bicalutamide treatment. ${ }^{27} \mathrm{~A}$ more comprehensive analysis of gene expression may highlight other changes in gene expression that are associated with the development of bicalutamide resistance and thus generate further novel targets for combination therapy with ADT.

A recent study ${ }^{8}$ in 247 patients treated with external beam radiotherapy identified that tumour oxygenation measurements were predictive of early biochemical failure, and Vergis et $a{ }^{9}{ }^{9}$ showed that increased expression of HIF1 led to early failure of both surgery and radiotherapy, indicating the importance of hypoxic cells in the development of metastatic disease. As we observed profound tumour hypoxia in our animal model in the 2 weeks following bicalutamide treatment, we investigated the effect of using the bioreductive drug AQ4N in combination with bicalutamide on both primary tumour growth and on metastatic spread. In hypoxic conditions, AQ4N is reduced to AQ4, a highly DNA-affinic cytotoxic compound that enhances the effects of both radiation $^{28,29}$ and chemotherapy. ${ }^{30,31}$ Supporting this approach is the evidence that AQ4 levels correlate with Glut1 expression in excised human tumours measured $24 \mathrm{hr}$ after administration of $\mathrm{AQ} 4 \mathrm{~N} .^{32}$ We found that combining bicalutamide treatment with a single dose of $\mathrm{AQ} 4 \mathrm{~N}$ administered on Day 7 resulted in increased primary tumour control and a reduction in the extensive metastasis observed with bicalutamide alone. Interestingly, AQ4N alone is the most effective in reducing metastasis. This can be explained by the predominant effect being exerted by AQ4N on the hypoxic cell compartment, that is, the more stress-resistant metastatic cells (the tumour still grows as the oxic cells are less affected by $A Q 4 N)$. The combination of bicalutamide and AQ4N allows 
targeting of both cell compartments, thereby reducing growth and extensive metastasis caused by bicalutamide alone. Our study clearly demonstrates that selection of a targeting strategy using the knowledge gained from the earlier experiments can significantly enhance the overall tumour response to bicalutamide. It is also consistent with other evidence that targeting hypoxic cells can reduce metastatic spread. ${ }^{33,34}$
Our study demonstrates proof-of-principle that targeting hypoxic cells has a therapeutic benefit in prostate cancer for both primary tumour control and reducing metastatic disease. Although our study demonstrates the effectiveness of treating androgen-sensitive cells, it may be advantageous to target castrate-resistant disease using combination therapy incorporating a bioreductive agent.

\section{References}

1. Semenza GL. Defining the role of hypoxiainducible factor- 1 in cancer biology and therapeutics. Oncogene 2009;29:625-34.

2. Lundgren K, Holm C, Landberg G. Hypoxia and breast cancer: prognostic and therapeutic implications. Cell Mol Life Sci 2007;22; 3233-47.

3. Movsas B, Chapman JD, Hanlon AL, et al. Hypoxia in human prostate carcinoma: an Eppendorf $\mathrm{pO}_{2}$ study. Am J Clin Oncol 2001;24:458-61.

4. Movsas B, Chapman JD, Greenberg RE, et al. Increasing levels of hypoxia in prostate carcinoma correlate significantly with increasing clinical stage and patient age. Cancer 2000;89: 2018-24.

5. Movsas B, Chapman JD, Hanlon AL, et al. Hypoxic prostate/muscle $\mathrm{pO}_{2}$ ratio predicts for biochemical failure in patients with prostate cancer: preliminary findings. Urology 2002;60: 634-9.

6. Turaka A, Buyyounouski MK, Hanlon AL, et al. Hypoxic prostate/muscle $\mathrm{pO}_{2}$ ratio predicts for outcome in patients with localized prostate cancer: long-term results. Int J Radiat Oncol Biol Phys 2012;82:433-9.

7. Rudolfsson SH, Bergh A. Hypoxia drives prostate tumour progression and impairs the effectiveness of therapy, but can also promote cell death and serve as a therapeutic target. Expert Opin Ther Targets 2009;13:219-25.

8. Milosevic M, Warde P, Menard C, et al. Tumour hypoxia predicts for biochemical failure following radiotherapy for clinically localised prostate cancer. Clin Cancer Res 2012;18:2108-15.

9. Vergis R, Corbishley CM, Norman AM, et al. Intrinsic markers of tumour hypoxia and angiogenesis in localised prostate cancer and outcome of radical treatment: a retrospective analysis of two randomised radiotherapy trials and one surgical cohort study. Lancet Oncol 2008; 9:342-51.

10. Shen M, Abate-Shen C. Molecular genetics of prostate cancer: new prospects for old challenges. Genes Dev 2010;24:1967-2000.

11. Osanto S, Van Poppel H. Emerging nove therapies for advanced prostate cancer. Ther $A d v$ Urol 2012;4:3-12.

12. Lekas A, Johansson M, Widmark A, et al. Decrement of blood flow precedes the involution of the ventral prostate in the rat after castration. Urol Res 1997;25:309-14.

13. Shibata Y, Ono Y, Kashiwaga B, et al. Hormona and morphological evaluation of the effects of antiandrogens on the blood supply of the rat prostate. Urology 2003;62:942-6.

14. Kaya C, Ozyurek M, Turkeri LN. Comparison of microvessel densities in rat prostate tissues treated with finasteride, bicalutamide and surgical castration: a preliminary study. Int J Urol 2005; 12:194-8

15. Jain RK, Safabakhsh N, Sckell A, et al. Endothelial cell death, angiogenesis and microvascular function after castration in an androgen-dependent tumour: role of vascular endothelial growth factor. Proc Natl Acad Sci USA 1998;95:10820-5.

16. Hansen-Algenstaedt N, Stoll BR, Padera TP, et al. Tumour oxygenation in hormone-dependent tumours during vascular endothelial growth factor-2 blockade, hormone ablation and chemotherapy. Cancer Res 2000;60:4556-60.

17. Butterworth KT, McCarthy HO, Devlin A, et al. Hypoxia selects for androgen independent cells with a more malignant geno-and pheno-type. Int J Cancer 2008;123:760-8.

18. Workman P, Aboagye EO, Balkwill F, et al. Guidelines for the welfare and use of animals in cancer research. Br J Cancer 2010;102:1555-77.

19. O'Rourke M, Ward C, Worthington J, et al. Evaluation of the anti-angiogenic potential of AQ4N. Clin Cancer Res 2008;14:1502-9.

20. Anderson J. The role of antiandrogen monotherapy in the treatment of prostate cancer. $B J U$ Int 2003:91:455-61.

21. Ohlson N, Wikström P, Stattin P, et al. Cell proliferation and apoptosis in prostate tumours and adjacent non-malignant prostate tissue in patients at different time-points after castration treatment. Prostate 2005;62:307-15.

22. Milosevic M, Chung P, Parker C, et al. Androgen withdrawal in patients reduces prostate cancer hypoxia: implications for disease progression and radiation response. Cancer Res 2007;67:6022-5.

23. Al-Ubaidi FLT, Schultz NS, Egevad L, et al. Castration therapy of prostate cancer results in downregulation of HIF1 levels. Int J Radiat Oncol Biol Phys 2012;3:1243-8.
24. Alonzi R, Padhani AR, Taylor NJ, et al Antivascular effects of neoadjuvant androgen deprivation for prostate cancer: an in vivo human study using susceptibility and relaxivity dynamic MRI. Int J Radiat Oncol Biol Phys 2011;80:721-7.

25. Denham J, Steigler A, Lamb DS, et al. Short-term neoadjuvant androgen deprivation and radiotherapy for locally advanced prostate cancer: 10-year data from the TROG 96.01 randomised trial. Lancet Oncol 2011;12:451-9.

26. DeMarzo AM, Nelson WG, Isaacs WB, et al. Pathological and molecular aspects of prostate cancer. Lancet 2003;361:955-64.

27. Mottet N, Bellmut J, Bolla M, et al. EAU guidelines on prostate cancer, Part 2: Treatment of advanced, relapsing and castration-resistant prostate cancer. Actas Urol Esp, 2011;35:565-79.

28. McKeown SR, Friery OP, McIntyre IA, et al. Evidence of a therapeutic gain when $\mathrm{AQ} 4 \mathrm{~N}$ or tirapazamine is combined with radiation. $\mathrm{Br}$ Cancer 1996;74:s39-s42.

29. Patterson LH, McKeown SR, Ruparelia K, et al. Enhancement of chemotherapy and radiotherapy of murine tumours by AQ4N, a reductively activated anti-tumour agent. Br J Cancer 2000;82: 1984-90.

30. Gallagher R, Hughes CM, Murray MM, et al. The chemopotentiation of cisplatin by the novel bioreductive drug AQ4N. Br J Cancer 2001;85: 625-9.

31. Friery OP, Gallagher R, Murray MM, et al Enhancement of the anti-tumour effect of cyclophosphamide by the bioreductive drugs AQ4N and tirapazamine. Br J Cancer 2000;82: 1469-73.

32. Albertella MR, Loadman PM, Jones PH, et al. Hypoxia-selective targeting by the bioreductive prodrug AQ4N in patients with solid tumors: results of a phase I study. Clin Cancer Res 2008; 14:1096-104.

33. Lunt SJ, Telfer BA, Fitzmaurice RJ, et al. Tirapazamine administered as a neoadjuvant to radiotherapy reduces metastatic dissemination. Clin Cancer Res 2005;11:4212-16.

34. DeClerck K, Elble RC. The role of hypoxia and acidosis in promoting metastasis and resistance to chemotherapy. Front Biosci 2010;15:213-25. 